valutata mediante una tecnica di immunoistochimica.

I nostri risultati indicano come la $\mathrm{p} 16^{\mathrm{INK} 4 \mathrm{~A}}$ sia sovraespressa nel $95.5 \%$ dei VIN e dei carcinomi HPV-correlati, mentre nelle lesioni neoplastiche e preneoplastiche non associate all'infezione da HPV la sovraespressione si evidenzia in una bassa percentuale (16.7\%). Per quello che riguarda le lesioni benigne, esse non mostrano un'aumentata espressione della p16 $6^{\text {INK4A }}$, indipendentemente dalla presenza del DNA di HPV (\% di positività del 27,3\%).

Questi dati confermano come le neoplasie vulvari si possano originare seguendo due vie patogenetiche distinte a seconda che siano legate o meno all'infezione da HPV ad alto rischio oncogeno. Inoltre, la sovraespressione della p16 $6^{\mathrm{INK} 4 \mathrm{~A}}$ risulta avere una specificità maggiore rispetto alla positività al DNA di HPV nel riconoscimento delle lesioni premaligne e maligne.

\title{
121
}

\section{CORRELAZIONE TRA PRESENZA DEL DNA DI HPV ED ESPRESSIONE DELLA PI I INKAA IN LESIONI BENIGNE E MALIGNE DELLA VULVA}

Ambretti S.' ',Venturoli S.', Cricca M.', Bonvicini F.', Santini D. ${ }^{2}$, Ceccarelli C.' ${ }^{2}$ Zerbini M.', Musiani M.'

1.D.M.C.S.S. Sez. di Microbiologia, Università di Bologna,

${ }^{2}$ D.C.S.R.I. Sez. di Anatomia Patologica,

Policlinico S.Orsola-Malpighi, Via Massarenti 9, 40I 38 Bologna

Secondo la più recente classificazione dei tumori della vulva, le neoplasie intraepiteliali (VIN) e i carcinomi a cellule squamose (VSCC) vengono distinti in due categorie in base all'eziopatogenesi e alle caratteristiche istologiche e cliniche. Il primo gruppo, caratterizzato istologicamente da lesioni di tipo basaloide o verrucoso, è correlato all'infezione da papillomavirus umani (HPV) ad alto rischio oncogeno, ed in particolare all'HPV16. Il secondo gruppo comprende invece lesioni istologicamente di tipo differenziato, che si presentano in donne più anziane e che non sono legate all'infezione da HPV.

In lesioni neoplastiche cervicali e di altri distretti dell'organismo, associate all'infezione da HPV ad alto rischio oncogeno, l'espressione della $\mathrm{p} 16^{\mathrm{INK} 4 \mathrm{~A}}$, una proteina coinvolta nella regolazione del ciclo cellulare, risulta aumentata, come conseguenza dell'azione delle oncoproteine virali.

Per studiare le modalità patogenetiche che differenziano le due categorie di neoplasie vulvari abbiamo valutato la correlazione tra la presenza del DNA di HPV e l'espressione della p16 ${ }^{\mathrm{INK} 4 \mathrm{~A}}$.

A questo scopo abbiamo analizzato 51 campioni istologici ( 11 condilomi e altre lesioni benigne, 22 VIN e 18 VSCC). La ricerca del DNA di HPV è stata effettuata mediante ibridazione in situ e PCR. L'espressione della p16 $6^{\mathrm{INK} 4 \mathrm{~A}}$ è stata 